\title{
Some imidazolines and their mixtures with inorganic anions as inhibitors of acid corrosion of steel
}

\author{
A.G. Berezhnaya, ${ }^{1}{ }^{\circledR *}$ E.S. Khudoleeva ${ }^{2} \mathbb{(}$ and V.V. Chernyavina ${ }^{1}(\mathbb{1}$ \\ ${ }^{1}$ Southern Federal University, st. Bolshaya Sadovaya 105/46, 344046, Rostov-on-Don, \\ Russian Federation \\ ${ }^{2}$ NPO NIIPAV, 62 Khimikov st., 347366, Volgodonsk, Rostov region, Russian Federation \\ *E-mail: Berezhnaya-aleksandra@mail.ru
}

\begin{abstract}
The effect of aminoethyloleylimidazoline (I), hydroxyethyloleylimidazole (II), diethylenediaminoleylimidazoline (III), potassium chloride, rhodanide, and iodide, as well as their mixtures on the corrosion of low-carbon steel in $15 \%$ sulfuric acid was studied by gravimetric method, by recording polarization curves, and by electrochemical impedance spectroscopy. It was shown that the investigated imidazolines at a concentration of $0.5 \mathrm{wt} \%$ protect steel by $74-$ $96 \%$ in the temperature range of $20-80^{\circ} \mathrm{C}$. The degree of protection by inorganic anions in the concentration range of $10^{-4}-10^{-2} \mathrm{~mol} / \mathrm{L}$ varies from 67 to $99 \%$ at $20^{\circ} \mathrm{C}$, depending on their nature. It was found that mixtures of imidazolines with the inorganic anions are more effective inhibitors of steel corrosion in sulfuric acid. They provide $95-99 \%$ protection of steel at $80^{\circ} \mathrm{C}$. The additives studied and their mixtures are mixed-type inhibitors. The inhibitory effect of the additives is due to a change in the structure of the electric double layer, the effective activation energy for corrosion, and blocking of a part of the steel surface.
\end{abstract}

Keywords: corrosion, low-carbon steel, sulfuric acid, inhibitor, imidazolines, potassium halides, potassium thiocyanate.

Received: April 19, 2021. Published: May 7, 2021

doi: $\underline{10.17675 / 2305-6894-2021-10-2-11}$

\section{Introduction}

Due to its good mechanical, chemical and physical properties, carbon steel is used in various industries. This steel is not resistant to acids, particularly in pickling applications. Sulfuric acid is used in pickling, descaling and chemical production. Sulfuric acid etching entails material losses due to metal corrosion. To reduce the metal consumption, corrosion inhibitors are added to pickling solutions. The known inhibitors of acid corrosion of steel belong to various classes of organic compounds. Among these, nitrogen-containing organic compounds as well as their mixtures with other compounds are distinguished [1-7]. The search for new corrosion inhibitors remains an urgent task and continues at present.

The purpose of this work is to study imidazoline derivatives and their mixtures with inorganic anions as corrosion inhibitors of low-carbon steel in sulfuric acid. 


\section{Experimental}

Samples with $0.5 \times 1 \mathrm{~cm}$ dimensions for polarization measurements and $1 \times 2 \mathrm{~cm}$ for corrosion measurements were cut from Steel 3 low-carbon steel. Before the measurements, the samples were cleaned with an abrasive cloth, degreased in alcohol, washed with distilled water, and dried with filter paper. The working electrolyte was a 15 mass $\%$ sulfuric acid solution.

(E)-2-(2-(Heptadec-8-en-1-yl)-4,5-dihydro-1H-imidazol-1-yl)ethan-1-amine or aminoethyloleylimidazoline (I), (E)-2-(2-(heptadec-8-en-1-yl)-4,5-dihydro-1H-imidazol-1-yl)ethan-1-ol or hydroxyethyloleylimidazole (II), (E)-2-(2-(heptadec-8-en-1-yl)-4,5-dihydro$1 \mathrm{H}$-imidazol-1-yl)ethan-1-ol or diethylenediaminoleylimidazoline (III), as well as potassium chloride, thiocyanate and iodide were studied as inhibitors of acid corrosion of steel.

The studied range of concentrations of imidazoline derivatives was $0.05-1$ mass $\%$, and that of inorganic compounds was $10^{-4}-10^{-2} \mathrm{~mol} / \mathrm{L}$. Mass loss measurements were carried out at temperatures of $20,50,65$ and $80^{\circ} \mathrm{C}$. The corrosion rate $K$ was calculated by the formula (1)

$$
K=\Delta m /(t \cdot S),
$$

where $\Delta m$ is the mass change in grams, $t$ is the experiment time in hours, and $S$ is the sample area in $\mathrm{m}^{2}$.

The efficiency of the additives was assessed by the inhibition coefficient $\gamma(2)$ and the degree of protection $Z(3)$ :

$$
\begin{gathered}
\gamma=K_{0} / K_{\mathrm{i}} \\
Z=\frac{K_{0}-K_{\mathrm{i}}}{K_{0}} \cdot 100 \%,
\end{gathered}
$$

where $K_{0}$ and $K_{\mathrm{i}}$ are the corrosion rates in pure acid without and in the presence of an inhibitor or mixture, respectively.

The mutual effect of inhibitors in mixtures was assessed by the coefficient of mutual effect [8]

$$
\sigma=\gamma_{\text {mix }} /\left(\gamma_{1} \cdot \gamma_{2}\right)
$$

where $\gamma_{\text {mix }}, \gamma_{1}$ and $\gamma_{2}$ are the experimental inhibition coefficient of the mixture and the inhibition coefficients of components 1 and 2.

Polarization measurements were carried out using a PI-50.01 potentiostat in a threeelectrode thermostatic cell at a temperature of $20^{\circ} \mathrm{C}$. A platinum counter electrode and a saturated silver chloride reference electrode were used. The potentials are given versus the latter. The polarization curves were recorded stepwise at $20 \mathrm{mV}$ steps. The potential was changed from the low value of $E=-0.7 \mathrm{~V}$ to a high value of $E=-0.3 \mathrm{~V}$. The sample was kept at each $E$ for one minute, then the current was recorded. Each curve was reproduced three times and the results were averaged. 
Capacitance measurements were carried out on an impedance meter (OOO Elins, Russia) in a two-electrode cell in the frequency range of $1 \mathrm{~Hz}-300 \mathrm{kHz}$ at the corrosion potential. A cylindrical platinum electrode served as the auxiliary electrode in the capacitance measurement circuit.

The electrode surface coverage was calculated by the formula:

$$
\theta=\left(C_{0}-C_{\mathrm{i}}\right) / C_{0},
$$

where $C_{0}, C_{\mathrm{i}}$ are the capacitances of the electric double layer in the acid solution without and with the inhibitor, respectively.

\section{Results and Discussion}

The investigated organic compounds are characterized by the presence of hydrophilic and hydrophobic groups. The hydrophobic part provides an inhibitory effect by forming a barrier layer on the metal surface. Together with other substituents, it can affect the effective electron density and steric conformation of the molecule, which determine the inhibitory effect. The tested compounds differ in their protective effect, Table 1.

Table 1. Dependence of the inhibition coefficient and the degree of protection of steel 3 on the concentration of imidazoline derivatives, $t=20^{\circ} \mathrm{C}$.

The values of $\gamma$ and $Z$ for additives

\begin{tabular}{ccccccc}
\cline { 2 - 7 } Concentration, \% & \multicolumn{3}{c}{ I } & \multicolumn{3}{c}{ II } \\
\cline { 2 - 7 } & $\boldsymbol{\gamma}$ & $\boldsymbol{Z}, \boldsymbol{\%}$ & $\boldsymbol{\gamma}$ & $\boldsymbol{Z}, \boldsymbol{\%}$ & $\boldsymbol{Z}$ & $\boldsymbol{Z}, \boldsymbol{\%}$ \\
\hline 0.05 & 12.69 & 92.11 & 32.96 & 96.97 & 28.47 & 96.49 \\
0.1 & 10.32 & 90.31 & 28.79 & 96.53 & 26.65 & 96.25 \\
0.25 & 11.26 & 91.12 & 33.85 & 97.05 & 29.13 & 96.57 \\
0.5 & 12.91 & 92.25 & 32.12 & 96.89 & 25.56 & 96.09 \\
1 & 14.89 & 93.28 & 27.23 & 96.33 & 21.41 & 95.33 \\
\hline
\end{tabular}

As one can see from the table, in this concentration range, the protective effect of additives I and II practically does not change. This may indicate the adsorption saturation of the steel surface with the inhibitor. The protective effect of inhibitor III decreases with increasing concentration. The degree of steel protection is higher than $90 \%$, and compounds II and III (hydroxyethyloleylimidazoline and diethylenediaminoleylimidazoline) are more efficient inhibitors.

The effect of inorganic salts on steel corrosion in $15 \%$ sulfuric acid solution is presented in Table 2. 
Table 2. Dependence of the inhibition coefficient and the degree of protection of low-carbon steel on the concentration of inorganic salts.

The values of $\gamma$ and $Z$ for additives

\begin{tabular}{ccccccc}
\cline { 2 - 6 } $\boldsymbol{C} \cdot \mathbf{1 0}^{3}, \mathbf{m o l} / \mathbf{L}$ & \multicolumn{2}{c}{ KCl } & \multicolumn{2}{c}{ KCNS } & \multicolumn{2}{c}{ KI } \\
\cline { 2 - 6 } & $\gamma$ & $\boldsymbol{Z}, \boldsymbol{\%}$ & $\boldsymbol{Z}$ & $\boldsymbol{Z}, \boldsymbol{\%}$ & $\boldsymbol{Z}, \boldsymbol{\%}$ \\
\hline 0.1 & 3.04 & 67.13 & 27.03 & 96.30 & 87.83 & 98.86 \\
0.5 & 2.29 & 56.36 & 43.02 & 97.68 & 108.10 & 99.07 \\
1 & 2.03 & 50.81 & 78.07 & 98.72 & 117.11 & 99.15 \\
5 & 11.98 & 91.65 & 100.38 & 99.00 & 124.00 & 99.19 \\
10 & 91.65 & 98.91 & 81.08 & 98.77 & 140.53 & 99.29 \\
\hline
\end{tabular}

Inorganic salts exhibit a protective effect against steel corrosion, and in most cases the protective effect increases with increasing salt concentration.

The protective effect of organic additives at $C=0.5 \%$ remains unchanged in the temperature range of $20-50^{\circ} \mathrm{C}$, and on heating to $80^{\circ} \mathrm{C}$ it decreases to $85.45,77.94$ and $74.24 \%$ for compounds I, II and III, respectively, Figure 1.

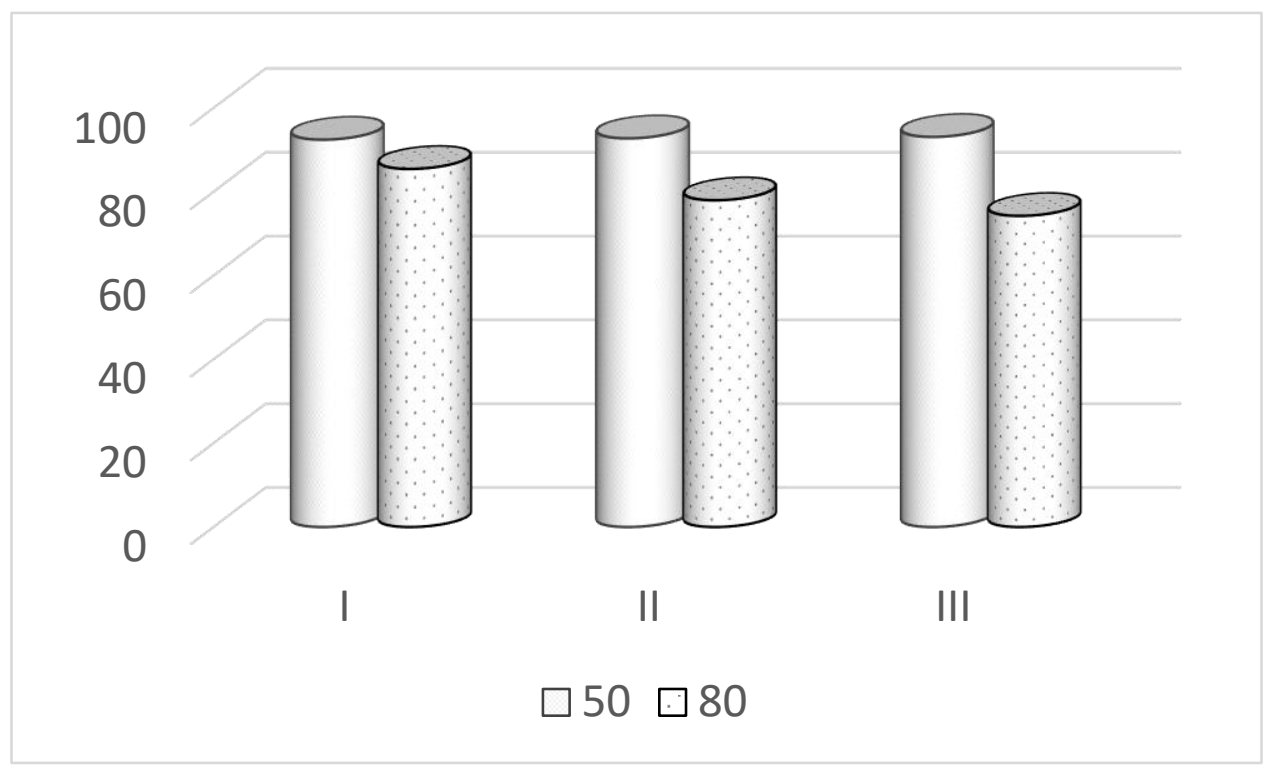

Figure 1. Degree of steel protection $(Z, \%)$ at 50 and $80^{\circ} \mathrm{C}$.

Organic additives increase the effective activation energy of the corrosion process by $10 \mathrm{~kJ} / \mathrm{mol}$.

Based on the effect on particular electrode corrosion reactions, imidazoline derivatives and inorganic salts are classified as mixed type inhibitors, Figure 2. 

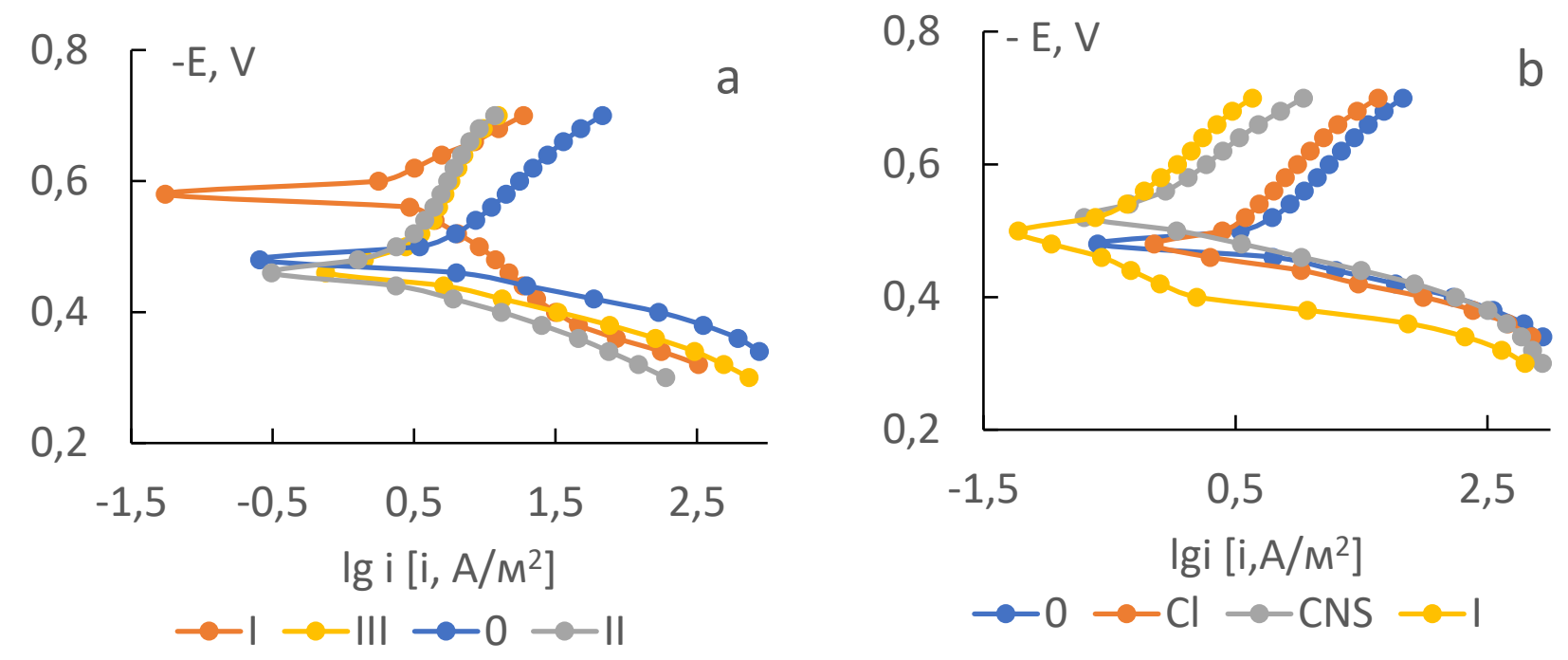

Figure 2. Polarization curves of steel in $15 \%$ sulfuric acid without (0) and in the presence of additives (I, II, III, $\mathrm{KCl}, \mathrm{KCNS}, \mathrm{KI}$ ). The concentration of organic compounds is $0.5 \%$, that of inorganic salts is $C=0.5 \mathrm{mmol} / \mathrm{L}$.

Compounds II and III nearly do not change the corrosion potential of steel $\left(E_{\mathrm{c}}\right)$. Aminoethyloleylimidazoline reduces $E_{\mathrm{c}}$ by $0.1 \mathrm{~V}$. This indicates its predominant effect on the cathodic hydrogen evolution. The investigated inhibitors differ in the effect on the polarizability of the cathodic reaction. In the presence of I, the Tafel coefficient $b_{\mathrm{c}}$ decreases threefold in comparison with $b_{\mathrm{c}, 0}$ observed in the sulfuric acid solution without additives. In the presence of compounds II and III, the Tafel coefficient $b_{\mathrm{c}}$ is almost two times higher than $b_{\mathrm{c}, 0}$. The rather large differences between the $b_{\mathrm{c}}$ and $b_{\mathrm{c}, 0}$ values may indicate a change in the mechanism of reduction of hydroxonium cations. The presence of all imidazolines in the solution leads to an increase in the Tafel coefficient $b_{\mathrm{a}}$. The most noticeable increase (almost twofold compared to the pure acid) is observed in the presence of aminoethyloleylimidazoline in the solution, Figure 2a. Potassium chloride and thiocyanate preferentially inhibit the cathodic hydrogen evolution, whereas potassium iodide reduces the rate of both electrode reactions, Figure 2b.

The inhibition coefficient of partial electrode reactions depends on the potential and on the nature of the inhibitor, Table 3.

By reducing the corrosion potential, potassium thiocyanate and compound I at some potentials stimulate the dissolution of steel, but with a further increase in $E$, they have an inhibitory effect.

As a rule, mixtures of inhibitors have a better protective effect against metal corrosion [9]. Indeed, the protective effect of mixtures of inorganic salts and the studied imidazolines is higher than that of individual substances, Table 4. 
Table 3. Dependence of the inhibition coefficient on the potential and nature of the inhibitor.

\begin{tabular}{ccccccc}
\hline & \multicolumn{5}{c}{ The values of $\boldsymbol{\gamma}$ for the additives } \\
\cline { 2 - 7 } & I & II & III & KCl & KCNS & KI \\
\hline 0.7 & 5.43 & 5.77 & 5.45 & 1.58 & 6.20 & 15.65 \\
0.64 & 8.79 & 4.07 & 3.92 & 1.76 & 8.16 & 15.96 \\
0.6 & 320.00 & 3.23 & 3.07 & 1.79 & 9.46 & 16.07 \\
0.54 & 1.34 & 2.29 & 2.00 & 1.76 & 18.90 & 19.77 \\
\hline & & & Anodic region & & 22.91 \\
0.46 & 0.34 & 20.32 & 8.40 & 3.15 & 0.59 & 73.88 \\
0.42 & 1.88 & 9.93 & 4.46 & 1.98 & 0.71 & 29.77 \\
0.38 & 4.13 & 13.90 & 4.60 & 1.44 & 1.10 & 4.14 \\
\hline 0.34 & 2.69 & 11.59 & 2.87 & 1.22 & 1.47 & \\
\hline
\end{tabular}

Table 4. Protective effect of mixtures depending on their composition and temperature.

Parameter values at temperatures

\begin{tabular}{|c|c|c|c|c|c|c|c|c|c|}
\hline \multirow[t]{2}{*}{ Parameter } & \multicolumn{3}{|c|}{$\mathrm{KCl}$} & \multicolumn{3}{|c|}{ KCNS } & \multicolumn{3}{|c|}{ KI } \\
\hline & I & II & III & I & II & III & I & II & III \\
\hline \multicolumn{10}{|c|}{$t=20^{\circ} \mathrm{C}$} \\
\hline$\gamma$ & 36.4 & 114.3 & 61.2 & 364.4 & 286.3 & 616.6 & 138.2 & 216.7 & 235.8 \\
\hline$Z, \%$ & 97.26 & 99.13 & 98.37 & 99.73 & 99.65 & 99.84 & 99.28 & 99.54 & 99.58 \\
\hline \multicolumn{10}{|c|}{$t=50^{\circ} \mathrm{C}$} \\
\hline$\gamma$ & 24.1 & 30.1 & 18.4 & 39.8 & 54.8 & 54.8 & 44.7 & 41.2 & 41.2 \\
\hline$Z, \%$ & 95.84 & 96.67 & 94.57 & 97.49 & 98.17 & 98.17 & 97.76 & 97.57 & 97.57 \\
\hline \multicolumn{10}{|c|}{$t=80^{\circ} \mathrm{C}$} \\
\hline$\gamma$ & 20.8 & 13.6 & 10.4 & 199.7 & 122.4 & 111.6 & 150.9 & 131.2 & 137.2 \\
\hline$Z, \%$ & 95.20 & 92.64 & 90.38 & 99.49 & 99.18 & 99.10 & 99.34 & 99.24 & 99.27 \\
\hline
\end{tabular}


With increasing temperature, the protective effect decreases in mixtures of imidazolines with potassium chloride. In the case of mixtures of thiocyanate and potassium iodide with imidazolines, the protective effect decreases more significantly at temperatures of 50 and $65^{\circ} \mathrm{C}$.

The coefficients of mutual effect of the mixture components $\sigma$ estimated by formula (4) as a function of the temperature are presented in Table 6.

Table 6. Dependence of the coefficient of mutual effect of the mixture components on the composition and temperature.

\begin{tabular}{ccccc}
\hline \multirow{2}{*}{$\boldsymbol{t},{ }^{\circ} \mathbf{C}$} & Imidazoline & \multicolumn{3}{c}{ Values of $\boldsymbol{\sigma}$ for mixtures of imidazolines with salts } \\
\cline { 3 - 5 } & & KCl & KCNS & KI \\
\hline \multirow{2}{*}{20} & I & 1.23 & 0.66 & 0.08 \\
& II & 1.56 & 0.21 & 0.05 \\
& III & 1.05 & 0.56 & 0.07 \\
\hline \multirow{2}{*}{50} & I & 1.74 & 0.24 & 0.08 \\
& II & 2.08 & 0.32 & 0.07 \\
& III & 1.21 & 0.30 & 0.09 \\
\multirow{2}{*}{80} & I & 3.01 & 3.93 & 0.33 \\
& II & 3.02 & 3.69 & 0.44 \\
& III & 2.68 & 3.90 & 0.54 \\
\hline
\end{tabular}

It is noteworthy that in mixtures with the highest inhibition coefficients, a mutual weakening of the protective properties of the components is mainly observed $(\sigma<1)$. An exception is a mixture of potassium thiocyanate with imidazolines at a temperature of $80^{\circ} \mathrm{C}$ $(\sigma>1)$. Regardless of the temperature, the mutual enhancement of the protective properties of the components is realized in a mixture of imidazolines with potassium chloride.

The effective activation energy of the corrosion process $\left(E_{\mathrm{a}}\right)$ also changes ambiguously in the presence of individual compounds and their mixtures in the sulfuric acid solution, Figure 3.

In the presence of mixtures of halides with the studied imidazolines, the $E_{\text {a }}$ values are nearly 2.0-2.5 times lower than in the acid solution without and in the presence of individual additives. A significant decrease in the effective activation energy indicates a change in the mechanism of the corrosion process, as well as a possible increase in the degree of surface coverage with an inhibiting mixture with an increase in temperature. 

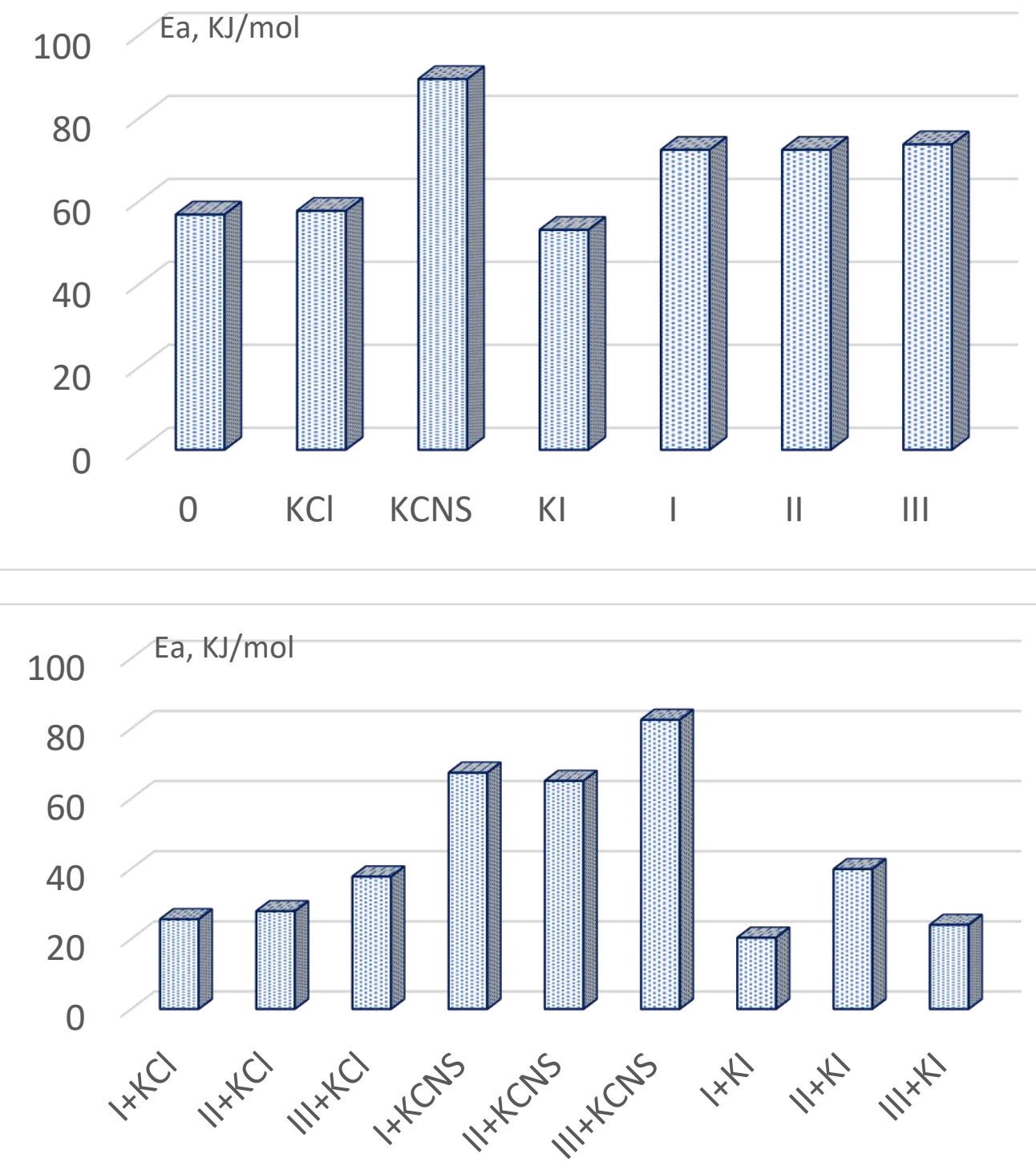

Figure 3. Effective activation energy of steel corrosion in the sulfuric acid solution without and in the presence of individual inhibitors, as well as their mixtures.

The mixtures of imidazolines with the studied inorganic anions are mixed inhibitors, Figure 4. 

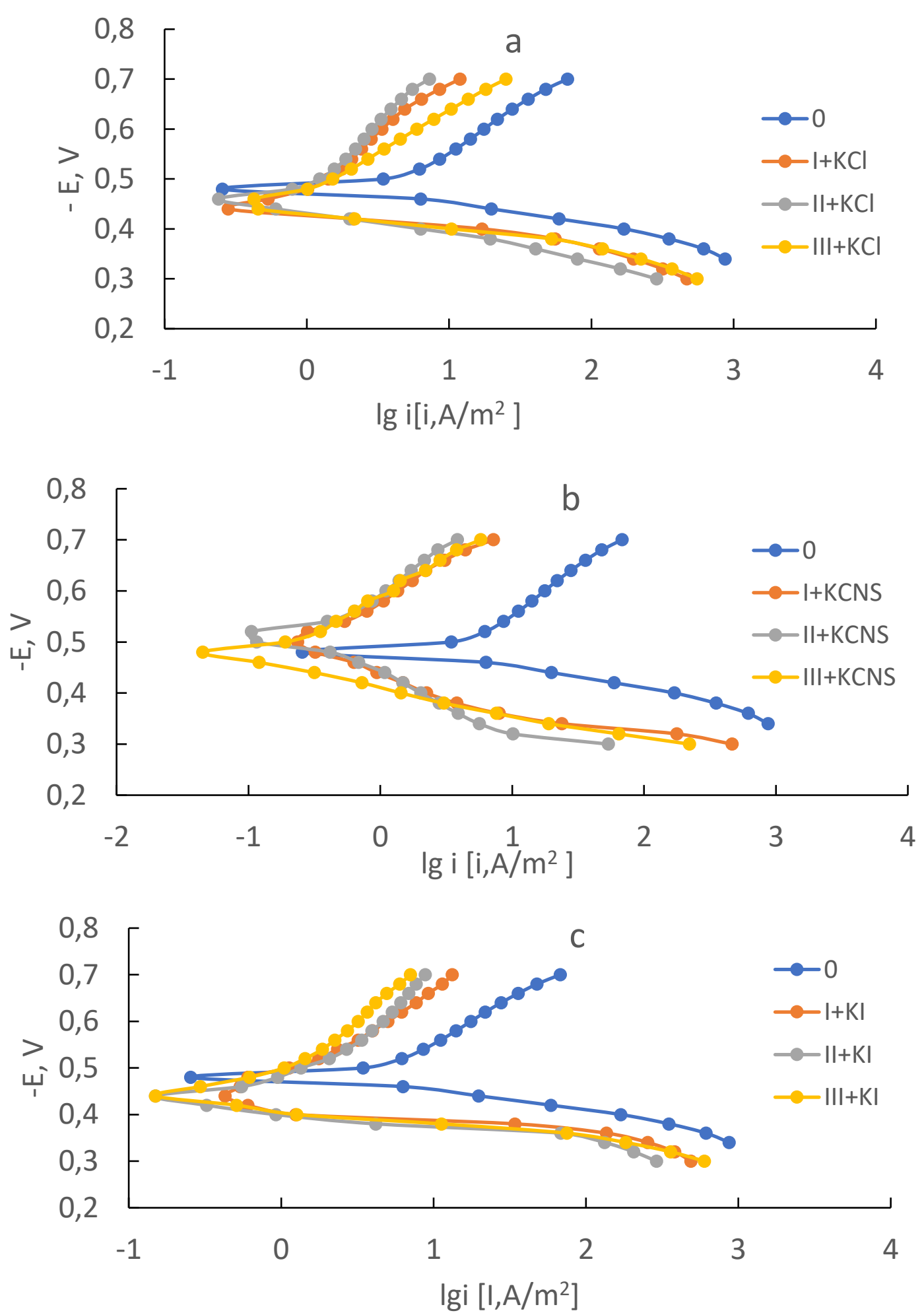

Figure 4. Polarization curves of steel in $15 \%$ sulfuric acid without additives (0) and in the presence of their mixtures. The concentration of imidazolines in the mixture is $0.5 \%$, that of inorganic anions is $C=0.5 \mathrm{mmol} / \mathrm{L}$. 

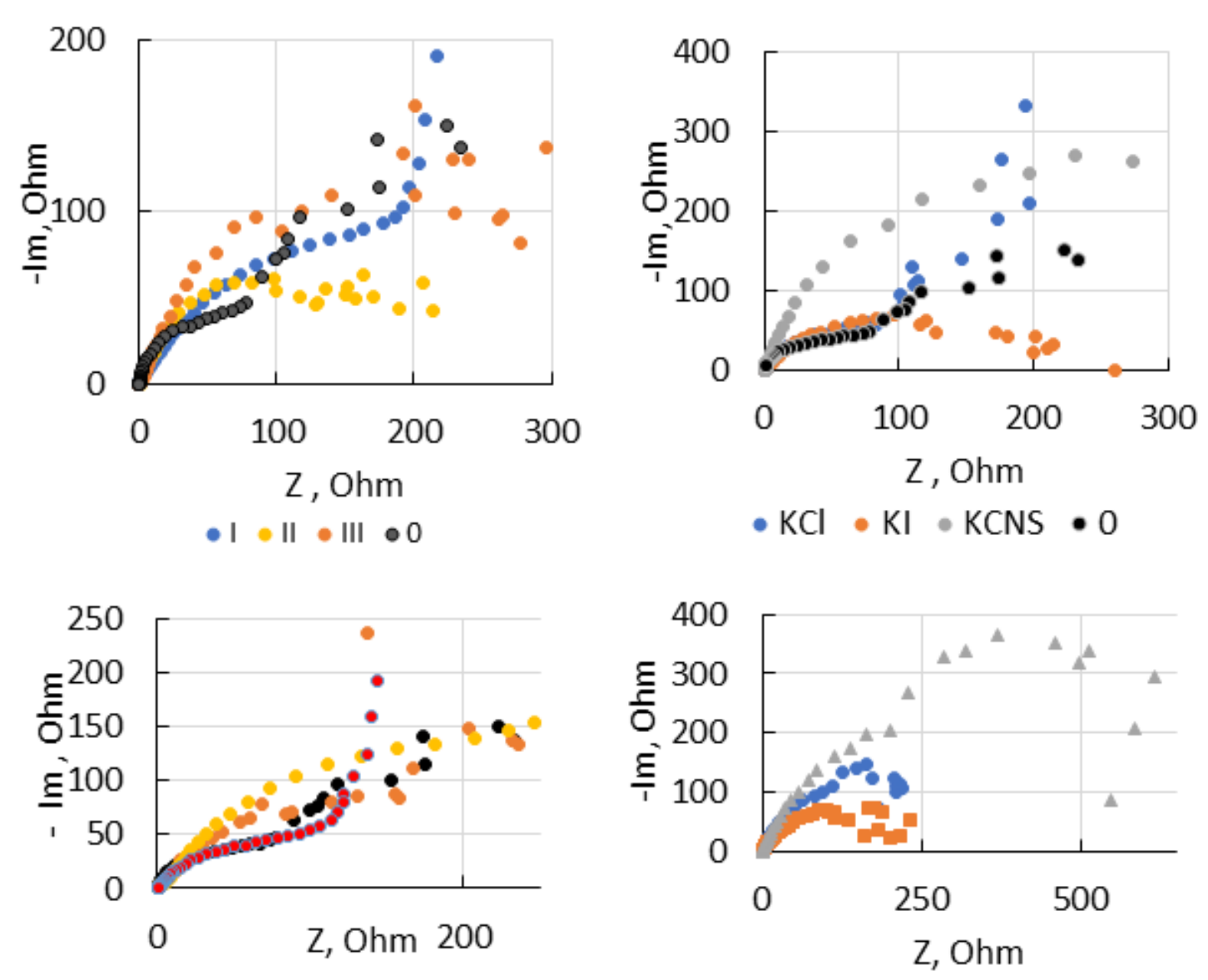

$\bullet 0 \cdot \mathrm{KCl}+\mathrm{I} \quad \mathrm{KCl}+\mathrm{II} \quad \bullet \mathrm{KCl}+\mathrm{III}$

- $\mathrm{Kl}+\mathrm{II} \quad \mathrm{Kl}+\mathrm{I} \quad \Delta \mathrm{Kl}+\mathrm{III}$

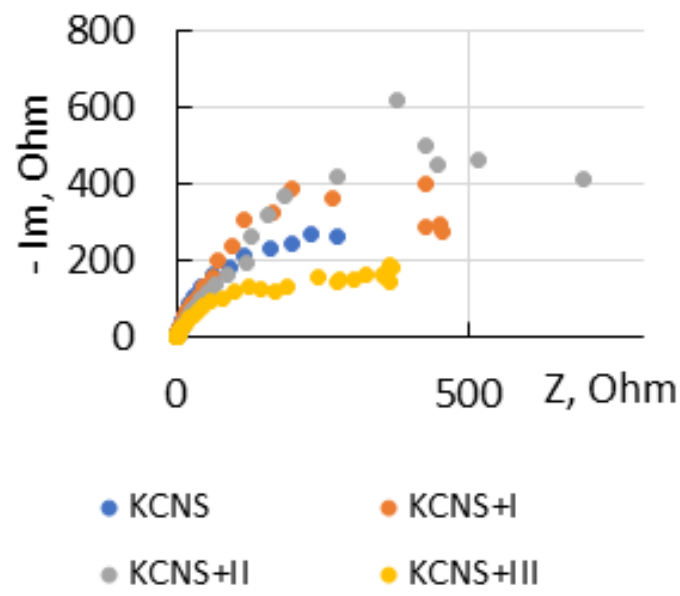

Figure 5. Nyquist plots of a steel electrode in sulfuric acid without (0) and in the presence of inhibitors and mixtures.

The inhibition coefficients of partial electrode reactions in the presence of mixtures are presented in Table 7. 
Table 7. Dependence of the inhibition coefficients of cathodic and anodic reactions by mixtures on the potential and composition.

\begin{tabular}{cccccccccc}
\hline & \multicolumn{7}{c}{ Values of $\boldsymbol{\gamma}$ for mixtures } \\
\cline { 2 - 10 }$-\boldsymbol{E}, \mathbf{V}$ & \multicolumn{7}{c}{ KCl } & \multicolumn{7}{c}{ KCNS } & & & KI & \\
\cline { 2 - 10 } & $\mathbf{I}$ & II & III & I & II & III & I & II & III \\
\hline 0.7 & 5.69 & 9.32 & 2.70 & 9.42 & 17.67 & 11.80 & 5.10 & 7.67 & 9.62 \\
0.64 & 5.71 & 7.14 & 2.70 & 12.60 & 16.29 & 12.72 & 3.62 & 4.56 & 6.65 \\
0.6 & 5.22 & 6.12 & 2.97 & 13.04 & 16.00 & 14.02 & 3.50 & 3.77 & 5.50 \\
0.54 & 4.16 & 4.56 & 3.20 & 16.07 & 21.77 & 18.70 & 3.67 & 3.19 & 4.61 \\
0.46 & 11.78 & 26.25 & 14.82 & 10.00 & 9.20 & 52.50 & 11.67 & 11.45 & 21.36 \\
0.42 & 27.81 & 29.55 & 27.24 & 39.93 & 39.93 & 81.52 & 97.69 & 181.85 & 115.88 \\
0.38 & 6.30 & 18.05 & 6.69 & 92.49 & 126.03 & 116.03 & 10.25 & 83.77 & 31.06 \\
0.34 & 4.39 & 10.92 & 3.90 & 36.63 & 154.67 & 46.03 & 3.41 & 6.56 & 4.77 \\
\hline
\end{tabular}

The mixture inhibit the ionization of steel more significantly than the individual additives, Tables 3,7 .

The Nyquist plots for steel in the sulfuric acid solution without and with individual additives, as well as with inhibitor mixtures, are shown in Figure 5.

$\Theta, \%$

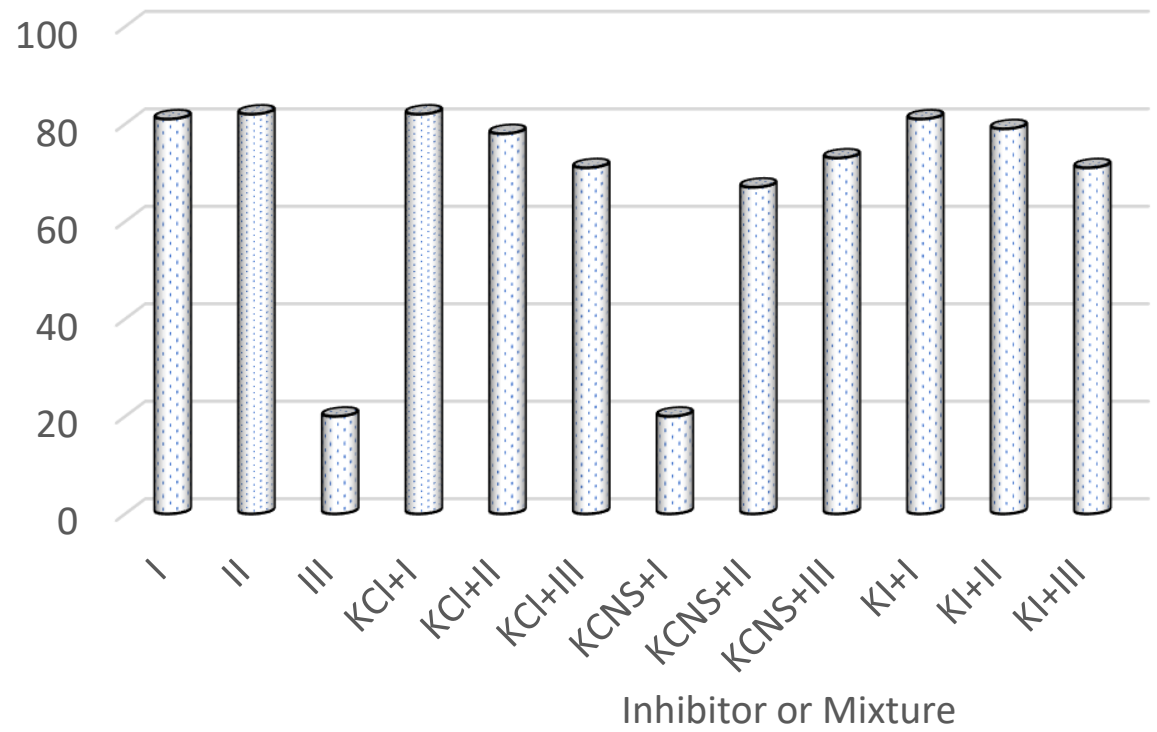

Figure 6. Dependence of the degree of surface coverage on the inhibitor nature and the mixture composition. 
The shape of the hodographs differs somewhat for imidazolines and their mixtures with inorganic anions. However, in most cases, the semicircle radius in the region of medium and high frequencies in the presence of inhibitors in the solution is larger than in the pure acid. This indicates that the inhibition of the corrosion process occurs due to the adsorption of the additives. In the low-frequency region, a decrease or an increase in resistance occurs relative to the values observed in the pure acid. The degrees of surface coverage with inhibitors $\theta$ estimated by equation (5) are shown in Figure 6.

For the majority of individual additives and mixtures, the values vary within the range of $70-82 \%$. The exceptions are additive III and mixture KCNS + I with $\theta=20 \%$. The investigated additives and their mixtures are adsorbed on the steel surface, block a part of it, and change the effective activation energy of the corrosion process.

\section{Conclusions}

1. The investigated imidazolines and inorganic salts in the considered concentration range are corrosion inhibitors of low-carbon steel in $15 \%$ sulfuric acid. Based on the decrease in efficiency, imidazolines and inorganic salts form the following series: hydroxyethyloleylimidazoline (II), diethylenediaminoleylimidazoline (III), aminoethyloleylimidazoline (I) and $\mathrm{KI}, \mathrm{KCNS}, \mathrm{KCl}$, respectively.

2. Mixtures of imidazolines and inorganic anions are more efficient inhibitors of acid corrosion compared to pure components. In the temperature range studied, the mixtures provide steel protection by $96-99 \%$. In mixtures of chloride ions and imidazolines, a mutual enhancement of the protective action of the components is observed. In the other mixtures, a mutual weakening of the protective action of the components prevails.

3. All the additives studied, as well as their mixtures, are mixed type studied. The inhibitors act by the activation-blocking mechanism of action.

\section{References}

1. Yu.I. Kuznetsov and L.P. Kazansky, Physico-chemical aspects of metal protection by corrosion inhibitors of the azole class, Usp. Khim., 2008, no. 3, 227-241 (in Russian).

2. S.P. Shpan'ko, V.P. Grigoriev, E.V. Plekhanova and V.A. Anisimova, Inhibiting and residual protective actions of the benzimidazole derivative during acid corrosion of iron, Zashch. Met. (Physicochemistry of the surface and protection of materials), 2010, no. 2, 208-213 (in Russian).

3. A.G. Berezhnaya, Gh.A.H. Shayea and V.V. Chernyavina, Mixtures of substituted pyridinium perchlorates with sulfur-containing organic compounds as inhibitors of acid corrosion of steel, Int. J. Corros. Scale Inhib., 2017, 6, no. 4, 372-383. doi: $\underline{10.17675 / 2305-6894-2017-6-4-2}$

4. K. Rasheeda, Vijaya D.P. Alva, P.A. Krishnaprasad and S. Samshuddin, Pyrimidine derivatives as potential corrosion inhibitors for steel in acid medium - An overview, Int. J. Corros. Scale Inhib., 2018, 7, no. 1, 48-61. doi: 10.17675/2305-6894-2018-7-1-5 
5. O.S. Bondar, S.V. Prihod'ko, I.M. Kurmakova and O.L. Humenyuk, Inhibiting action of nitrogen-containing heterocycles in corrosion of low-carbon steel, Mater. Sci., 2011, 47, no. 3, 370-374. doi: 10.1007/s11003-011-9405-6

6. A.G. Berezhnaya, V.V. Chernyavina and L.M. Astakhova, Imidazobenzimidazole hydrochloride derivatives as steel inhibitors in hydrochloric acid, Int. J. Corros. Scale Inhib., 2020, 9, no. 1, 313-319. doi: 10.17675/2305-6894-2020-9-1-20

7. Ya.G. Avdeev, M.V. Tyurina and Yu.I. Kuznetsov, On the inhibition of corrosion of lowcarbon steel in phosphate media by a triazole derivative, Bulletin of the Tambov University. Series: natural and technical sciences, 2013, no. 5, 2258-2261 (in Russian).

8. V.V. Ekilik and O.V. Chikov, Some diagnostic criteria for the mutual influence of inhibitors of acid corrosion of metals, Prot. Met., 1991, 27, no. 1, 72-82 (in Russian).

9. O.A. Goncharova, A.Yu. Luchkin and N.N. Andreev, Mixed volatile corrosion inhibitors of ferrous metals and universal preparations, Korroz.: Mater., Zashch. (Corrosion: Materials, Protection), 2021, no. 2, 33-40 (in Russian). doi: 10.31044/1813-7016-2021$\underline{0-2-33-40}$ 